\title{
"Alkaline Chlorine Dioxide Bleaching Of Cloned Eucalyptus Hybrid Wood 2013 and Its Environmental Impact",
}

\author{
Sankaralingam.$P^{1}$., Sankar.A ${ }^{2}$., \\ ${ }^{1}$ Research Scholar, ${ }^{2}$ Assistant professor, Department of chemistry, Kandaswami Kandars college, Paramathi - \\ Velur, Namakkal District, Tamilnadu, India -638 182.
}

\begin{abstract}
The bleaching chemistry indicates that $p H$ affects the effectiveness of chlorine dioxide treatment and the standard recommendations has been to maintain a final stage $\mathrm{pH}$ range for brightening with chlorine dioxide between 3.5 and 4.0. But we used 16\% \& 17\% TAA cooked Clone EH2013 of kappa number 18.7 \& 17.4 without Oxygen Delignification (ODL), were bleached in Acidic and Alkaline pH initial chlorine dioxide $\left(D_{O}\right)$ stage, followed by Caustic reinforced Hydrogen peroxide (Ep) and final Chlorine dioxide $\left(D_{l}\right)$ stage of bleaching. At constant bleaching condition both EH2013 pulps show these alkaline pH bleaching methods can improve the pulp bleachability without affecting pulp strength properties, optical properties, and physical properties and improved effluent characteristics. The Alkaline $\mathrm{pH}$ bleached pulp final brightness $85.7 \%$ ISO (16\% TAA) and $86.5 \%$ ISO (17\% TAA) are well compared to Acidic pH final brightness $83.4 \%$ ISO (16\% TAA) and $84.4 \%$ ISO (17\% TAA) initial chlorine dioxide bleaching and followed by extraction reinforced Hydrogen peroxide and final Chlorine dioxide bleaching. The fiber length, width and curl index of Acidic and Alkaline $p H$ bleached pulp has not shown any distinct variation, but alkaline $\mathrm{pH}$ bleached pulp has shown slightly higher than Acidic pH bleached Pulp. Both 16\&17\% TAA cooked pulps filtrate analysis of the Alkaline pH Do stage, shows lower Colour (14.6 \& 15.4\%), Total Dissolved Solids (10.7\& 17.9\%) and COD (14.2 \& 18.0\%) than Acidic pH Do bleaching filtrate. Based on results from the Acidic and Alkaline pH bleaching of EH2O13 pulp, we found that the optimum $\mathrm{pH}$ for initial Do and final $D_{1}$ chlorine dioxide bleaching stage should be operated with a final $\mathrm{pH}$ close to alkaline, when a typical chlorine dioxide charge is applied and its effluent characteristics shows lesser inorganic load when compared to acidic effluent
\end{abstract}

Keywords: alkaline bleaching, acidic bleaching, clone EH, Chemical Oxygen Demand, Fiber length.

\section{Introduction}

Pulp and paper making is a resource-depletion process that consumes large amounts of energy, water, trees and fillers. It is a mature industry that is innovative and adapts intermittently to technological change in order to remain competitive and penetrative in the National and International market. The emergence of this technology took place during the latter half of the nineteenth century, a time when there was little thought given to the possible detrimental effects of industrial pollution on the environment or human health. In the United States, pulp and paper mills are now considered the nation's third largest polluter (1). In Canada, it has been estimated that this industry is responsible for $50 \%$ of all the waste dumped into the nation's waters (2) and also accounts for approximately 5.6\% of the common air contaminants from known industrial sources (3)The emerging technologies exist for substantially reducing emissions, particularly those that are a great risk to present and future generation. However, pulp and paper mills represent capital expenditures in the high hundreds of millions of dollars, and retrofitting a pulp and paper mill with new process technologies for pollution abatement regularly costs additional hundreds of millions of dollars. Such huge expenditures put pulp and paper mills at a disadvantage with competitors with Developed countries without stringent effluent controls. The implementation of environmental protection will have to proceed in a manner that sustains the economic health of the pulp and paper industry, yet ensures human health and environmental quality.

To tackle this problem in a cost-effective manner it is necessary to understand the nature of the problem, and identify the specific components that endanger human health and environmental quality. It is then possible to choose and install new process technologies to prevent the production of toxic effluents. Alternatively, depending upon economic circumstances and the age of the mill, it may be more cost-effective to add an end-of-pipe waste water treatment system. There is a large degree of variation in the pulping and bleach plant technologies used in mills. Accordingly, the solution for one mill cannot be applied to the environmental problems of the whole pulp and paper industry.

Most of the world's bleached pulp is presently treated using oxygen delignification. Oxygen delignification is a process which uses oxygen and alkali to remove a substantial fraction of the lignin that remains after pulping. During oxygen delignification, it has been confirmed that the number of phenolic hydroxyl groups and carboxyl groups in the lignin decreases and the number of carboxylic acid groups 
increases. The final degradation products from oxygen delignification are predominately organic acids and carbon dioxide.

Physical properties of paper depend both on fiber to fiber bonding and on the intrinsic fiber strength of the pulp. However, reductions in pulp viscosity are usually significant only at low freeness values when the paper is well bonded and fiber failure determines paper strength. Moreover, because high pressures are involved in oxygen delignification, the cost of an oxygen system can require a significant capital investment. The random attacks on the cellulose chain decrease the average length of the cellulose, as indicated by a decrease in pulp viscosity, which if excessive, leads to the loss of pulp strength.

It is easier to delignify pulps with high rather than low initial kappa numbers. It has been reported that southern hardwood kraft pulps with high initial kappa number have lower resistance to oxygen delignifcation and a higher reaction rate compared to pulps with low initial kappa number (4). The reason for this observation is that the kappa number represents a combination of different oxidizable components: lignin, nonlignin oxidizable structures, and hexenuronic acids (HexA) (5), and the relative contribution of HexA, which are unreactive under standard oxygen delignification conditions, decreases with increasing kappa number. Also certain portions of the adsorbed compounds adhere very firmly to the Cellulose fibers and behave almost like native lignin with regard to the action of strong mineral acids and mild oxidation. This can stimulate higher lignin content in analysis (HermannF.J.).

The pulp bleachability of initial Chlorine dioxide treatment would be directly related to the amounts of phenoxy groups present in the lignin as per the literature. This result was significant since most bleaching text books $(6,7)$ assert that the $\mathrm{ClO}_{2}$ bleaching chemistry occurs primarily via phenoxy groups and that this unit in lignin controls pulp bleachability. To define the influence of $\mathrm{pH}$ on $\mathrm{ClO}_{2}$ bleaching of Eucalyptus pulps, a Laboratory cooked pulps of $16 \%$ and $17 \%$ white liquor (TAA) addition was prepared, analysed, and bleached without Oxygen Deligninfication (ODL) stage via $\mathrm{DoEpD}_{1}$ sequence. The present bleaching study relates to a process for the delignification and bleaching of an aqueous lignocellulosic pulp under acidic and alkaline $\mathrm{pH}$ conditions in the initial Chlorine dioxide bleaching sequence and its environmental impacts. The changes in pulp bleaching at acidic and alkaline $\mathrm{pH}$ bleached pulp were evaluated to determine the bleachability of Cloned EH2013.

Stringent regulation of pulp and paper mill discharge by nodal authorities and public awareness will necessitate large capital expenditures by the industry. Consequently, these regulations will ensure modified pulping, bleaching, improved environmental quality, and a reduction of the risk to human health that is posed by this vital industry.

Research and the development of new processes and techniques to curtail the release of filtrates from pulp mills are following approaches. The first strategy is the development of new pulping processes with emphasis on improved delignification without ODL, and the replacement of Sulphuric Acid for bleaching. The second approach is the development of new alkaline bleaching processes, particularly individual or mixed wood species have advantages for effluent characteristics. These finding has been confirmed more recently both in the Laboratory (8) and on a mill scale (9).

\section{Experimental}

Raw material preparation: Cloned Eucalyptus Hybrid 2013 are developed and planted an experimental scale in TNPL plantation area for high yield and quality pulping purposes. Economically, this is an important species for the tropical farmers, to whom this provides an insurance against agricultural failure. In TNPL, The breeding programs of various wood clones were established with IFGTB, Coimbatore. The species of EH2013 were developed and may introduce into farm forestry under the TNPL intensive plantation, and this has attracted the attention of farmers in drier tracts of the state, due its adaptation to the arid conditions.

Four year old Clone EH2013 tree was cut, debarked, cut into wood logs and chipped in a mill Disc chipper and screened in a standard laboratory Chip screen and the accepted chips were air dried at room temperature. After getting constant moisture, the chip are packed in a polythene bag and stored for a day to get homogeneous moisture of the chip before cooking.

Pulping: The chips were pulped (alkali charge $16 \%$ and $17 \%$ as $\mathrm{Na}_{2} \mathrm{O}$, Liquor to wood ratio $\mathrm{L}$ : $\mathrm{W}=2.8: 1$ cooking temperature: $165^{\circ} \mathrm{C}$, time: 65 minutes) in a Laboratory bomb digester. At the end of cooking, the contents of the bomb were discharged into a bowl followed by sequential washing with DM water, disintegrated in a rod mill for 20 minutes, screened on a flat - slotted laboratory screen (slot width $0.15 \mathrm{~mm}$ ), centrifuged, and then granulated. Total pulp yield, amount of screen rejects, kappa number and black liquor properties were determined using TAPPI standard methods. After dewatering and fluffing, kappa number, percentage rejects, and total yield were determined. The unbleached pulp properties were listed in Table: I. The lack of certain excess of free alkali in the final stage of the cook can cause a shift of the dynamic equilibrium between the 
decomposition of the wood chips and the sorption leads to increase desorption of the organic substances dissolved in the cooking liquor.

The Cooked and screened EH 2013 pulp thus rendered deficient in alkali and enriched in organic material should therefore be removed and replaced by small amounts of fresh alkali in order to obtain well-cooked pulps ,light in colour and lower pentosen content.

\title{
Bleaching
}

Pulp bleaching is a process whereby wood pulp is whitened by sequential bleaching and extraction. Under acid or alkaline conditions, chlorine dioxide reacts oxidative with colour causing organic compounds, degrading them and increasing the brightness of the pulp. Alkaline stages, with or without chemicals such as oxygen and hydrogen peroxide, are used between the acidic oxidizing stages to solubilise and remove the reacted material from the pulp. Bleach filtrate from each step of pulp bleaching are usually analysed to identifying organic compounds that are toxic or that could cause oxygen depletion and dissolved solids causes surface scale in land.

\begin{abstract}
Alkaline pH bleaching
During bleaching process, light scattering is retained and light absorption is reduced. The illusion of whiteness in bleaching is created by eliminating light absorption from pulp by the reduction of Chromophore group present in the fiber. Chlorine dioxide is commonly used as bleaching agent today in majority of pulp mills throughout the world $(10 \& 11)$. It is a general practice to maintain the pulp pH at 2-2.5 in the $\mathrm{D}_{\mathrm{HT}}$ stage (12) and it is maintained by the addition of Sulphuric acid. However, addition of Sulphuric acid has negative effects on environment and pipe line scale properties for example increasing calcium Sulphate scale. The solubility of calcium Sulphate scale is a temperature dependent. The solubility of calcium Sulphate scale in water decreases with increase temperature. In other words, Calcium Sulphate scale is soluble in cold water but almost completely insoluble in super-heated water. Consequently, Calcium Sulphate gets precipitated and form hard scale on the surfaces of the pipe lines. Acid stage bleach plant effluent, which is let out from the pulp mill, will also have high TDS, Sulphate and temperature and needs special attention during downstream effluent treatment. At Higher $\mathrm{pH}$, higher molecular weight lignin fragments soluble in alkali, at base concentrations of $0.5-1 \%$ and $\mathrm{pH} \sim 12$, but some portion is insoluble even at severe alkaline conditions. The alkaline environment also decreases lignin's hydrodynamic volume, allowing greater diffusion from the cell wall (13, 14 and 15). Several sodium hydroxide reactions with lignin increase the solubility of the lignin.

Freshly prepared solutions of Chlorine dioxide solution and other bleaching and extracting chemicals Sodium Hydroxide and hydrogen peroxide were prepared in the lab. Water and bleaching or extracting chemicals were added to $250 \mathrm{~g}$ of oven dried pulp in polyethylene bags. The bags were kneaded by hand and placed in a temperature controlled water bath. After each of the bleaching stages, pulp was filtered to collect the spent bleaching liquor. The $\mathrm{pH}$ of the spent liquors was measured, and the liquors stored in plastic containers. Between bleaching stages, the pulp was washed with clean water, which was filtered from the pulp and discarded. The brightness of a sub sample of bleached pulp was measured according to the standard TAPPI Test Method (T 452) to ensure that Laboratory scale bleaching produced pulps at a final brightness of $87 \%$ ISO.

Unbleached EH2013 pulps were prepared from laboratory cooking process was used without Oxygen Delignification. The two pulps were bleached in the laboratory to achieve a target brightness of \% ISO according to the following stage bleaching sequence: $\mathbf{D}_{\mathbf{0}} \mathbf{E}_{\mathbf{P}} \mathbf{D}_{1}$. The use of chlorine dioxide at lower and higher pH in the first stage has been studied EH2013 pulp, and typical application and its impact on effluent generation are discussed elsewhere.
\end{abstract}

The following $\left(\mathrm{DoEpD}_{1}\right)$ bleaching sequences were carried out for EH2013 wood pulps:

\section{$D_{0}$ Stage}

Screened EH2013 pulps of $10 \%$ consistency without ODL stage were used and their $\mathrm{pH}$ was adjusted to Acidic and Alkaline stage for $\mathrm{ClO}_{2}$ bleaching experiments. Then freshly collected $\mathrm{ClO}_{2}$ was added into the polythene bags and the pulp was mixed well and noted its $\mathrm{pH}$ and put the pulp contained polythene bags in a preheated water bath at $75^{\circ} \mathrm{C}$ for 90 minutes with intermittent mixing of the pulps. After noted the end $\mathrm{pH}$ of the pulps and the pulps were filtered, washed with hot water followed by DM water and thickened the pulps for preparing second bleaching stage. Kappa number and optical properties of the washed pulps were determined. The $\mathrm{D}_{\mathrm{O}}$ bleaching conditions, physical and optical properties were as in table: II\&III.

\section{Ep Stage}

The pulps from the $\mathrm{D}_{0}$ stage were adjusted to $10 \%$ consistency with $\mathrm{DM}$ water and $\mathrm{NaOH}$ addition was chosen to yield a terminal $\mathrm{pH}$ of 10.2-10.5. After noted the $\mathrm{pH}, 1.0 \%$ Hydrogen peroxide was added and noted 
the pulp mixture $\mathrm{pH}$. Then (Ep) bleaching stage was performed in a preheated water bath at $75^{\circ} \mathrm{C}$ for $90 \mathrm{~min}$. At the end of the (Ep) stage, the pulps $\mathrm{pH}$ were noted and filtered. The filtrates were collected, and the pulp was thoroughly washed with hot water followed by DM water and thickened pulp for final chlorine dioxide $\left(D_{1}\right)$ bleaching stage. The Ep bleaching conditions, physical and Optical properties were as in table: II\&III.

\section{$D_{1}$ stage}

The pulps from the Ep stage were adjusted to $10 \%$ consistency with DM water and $0.8 \%$ chlorine dioxide charge was chosen to all pulps to achieve a target Brightness ( $87.0 \% \mathrm{ISO})$.After noted the pulps $\mathrm{pH}$, $\left(\mathrm{D}_{1}\right)$ stage was performed in a preheated water bath at $75^{\circ} \mathrm{C}$ for $120 \mathrm{~min}$. After noted the pulps end $\mathrm{pH}$, the pulps were filtered and the filtrates were collected, and the pulp was thoroughly washed with hot water followed by DM water. The thickened pulps were stored in polythene bags for determination of its strength and optical properties. The $\mathrm{D}_{1}$ bleaching conditions, physical and optical properties were as in table: IV\&V.

Pulp characterization: At all stages brightness, kappa number and strength properties of the pulps were carried out as per TAPPI standard methods. Pulp brightness was measured with an optical Spectrometer by using white tiles as standard. For calculating tear, tensile and burst indices, the hand sheets were made as per ISO DP 5269 and dried on plates in standard conditions and conditioned at $27 \pm 1^{\circ} \mathrm{C}$ and $65 \pm 5 \%$ relative humidity and tested according to TAPPI standards. Hand sheet properties are reported on an oven dry basis. The unbleached and bleached pulp properties of EH2012 were shown in table: IV \& V.

Fiber analysis: The determination of average pulp fiber geometrics was a tedious work involving microscopy until the 1980. Equipment for these determinations, based on a flow of a much diluted pulp suspension trough a cell, the recording of pictures of the pulp constituents by 2D CCD camera and picture analysis software, was then developed. In this work Fiber Lab, Metso Automation has been used to determine pulp fiber properties: The Fiber Lab analyser automatically measures classifies and reports on the dimensional properties of fiber samples. Approximately 20000 fibers were measured in each sample, and the mean fiber length, fiber width, fines, cell wall thickness and shape factor (curl) are examples of properties that can be measured or calculated. The measured values are tabulated in Table VI \&VII [Metso Automation. - FiberLabTM, Research-quality fibre measurement for mill process management, Leaflet, 2001.]

Effluent analysis: Low carry over to bleaching and a low carryover amount of filtrate in each bleach stage is very important. At all stages, the filtrate were collected and tested as per standard testing methods. Effluent characteristics like Colour, Total Dissolved solids (TDS) inorganic and Chemical Oxygen Demand (COD) were measured and the tested values listed in table: VIII \& IX.

\section{Results And Discusion}

The oxidized lignin compounds remains in the pulp fiber after the Do stage, and can only be removed by a subsequent alkaline extraction stage. As expected, the charge of sodium hydroxide necessary to extract the oxidized, water-soluble material quantitatively is related to the kappa number of the pulp entering the $\mathrm{D}_{0}$ stage .The $\mathrm{pH}$ profile has a major effect in determining the efficiency of chlorine dioxide bleaching. The screened pulp thus rendered deficient in alkali and enriched in organic material should therefore be removed and replaced by small amounts of fresh alkali in order to obtain well-cooked pulps, light in colour and lower pentosen content. During acidic or alkaline $\mathrm{pH}$ bleaching, the $\mathrm{pH}$ is decreased considerably during the first reaction phase due to the formation of organic and hydrochloric acids. Hence, sodium hydroxide must be added to maintain the optimal end $\mathrm{pH}$ in the range between 6.0 and $5.9\left(\mathrm{D}_{0}\right)$. According to Reeve and Rapson, approximately $0.6 \mathrm{~kg}$ $\mathrm{NaOH}$ should be added for each $\mathrm{kg} \mathrm{ClO}_{2}$ charged to the air dried ton of pulp to ensure an optimal end $\mathrm{pH}$ but in this alkaline $\mathrm{pH}$ Do stage followed by extraction stage has consumed $0.45 \mathrm{~kg} \mathrm{NaOH}$ instead of $0.9 \mathrm{~kg}$ consumed by acidic $\mathrm{pH}$ Do stage.

The chemistry of bleaching might not be as obscure as some of the earlier reviews have indicated; the complexity of the partial reactions makes it extremely difficult to understand the overall effect. Obviously there is need for a full computational simulation package that can bind together the kinetics and equilibria of chemical reactions and mass transfer (Kuitunen et al. 2005).

Although the chlorine dioxide speciation into chlorite, chlorate, chloride and organically bound chlorine, etc. is quite well investigated for "normal $\left(60-70^{\circ} \mathrm{C}\right)$ " chlorine dioxide delignification/bleaching and brightening (Chang et al. 2001; Ni 1992; Rapson, Strumila 1979; Strumila, Rapson 1976).

Reducing the bleaching chemical consumption, yet reaching the target brightness has important cost and environmental consequences. Bleach chemical consumption at the first stage is a function of pulp kappa number; the extracted kappa number that decides the bleach chemical consumption in the following stages depends on first-stage delignification. The changes made in pulping could influence the bleaching response of 
pulps. Therefore, it is important to determine whether the use of digester additives or oxygen delignification stage would impact the bleachability of pulps. But high kappa bleaching of EH2013 shows better delignification and brightness development in initial chlorine dioxide, which enhances the bleachability of extraction followed by final chlorine dioxide stage to get the required brightness.

It has been reported that southern hardwood kraft pulps with high initial kappa number have lower resistance to oxygen delignifcation and a higher reaction rate compared to pulps with low initial kappa number (Hart et al. 2011). The reason for this observation is that the kappa number represents a combination of different oxidizable components: lignin, nonlignin oxidizable structures, and hexenuronic acids (HexA), and the relative contribution of HexA, which are resistant to Oxygen and Hydrogen peroxide treatment (Tenkanean et al.1999, Ragnar 2001).In this study of EH2013 wood pulp shows the trend of consume slightly excess chlorine dioxide at higher kappa without ODL.

Results indicative in Table: II \& III, no marginal change in bleaching efficiency was noticed between acidic and alkaline $\mathrm{pH}$ delignification of the EH2013 pulps. In spite of the fact that same $(1.80 \%) \mathrm{ClO}_{2}$ was consumed in both experiments; the kappa number after extraction was more or less identical. Previous works have shown that Lignin reduces $\mathrm{ClO}_{2}$ to Chlorous acid or Chlorite ion depends on $\mathrm{pH}$ and hypochlorous acid in parallel reaction. In the present case, EH2013 pulp delignification efficiency in the $\mathrm{D}_{0}$ stage, expressed as kappa number reduction was $63.6 \& 65.5 \%$ for the Acidic $\mathrm{D}_{0}$ stage, as compared with $65.3 \% \& 64.9 \%$ for the alkaline pH initial $\mathrm{ClO}_{2}$ bleached EH2013 Pulp.

In the case of the acidic or alkaline $\mathrm{pH}$ pulps, as shown in Table: II \&III, there was no Brightness variation with respect to delignification efficiency, which is sensitive to operating conditions and perhaps also to unbleached pulp characteristics. In this regard, it is worth noting that alkaline $\mathrm{pH}$ bleaching method was made an attempt to optimize the $\mathrm{ClO}_{2}$ addition, for bleaching performance of EH2013 pulp and its filtrate properties are better than acidic filtrate for the environmental concern.

It is apparent that there is no difference in $\mathrm{D}_{0}$ (Ep) delignification efficiency between acidic and alkaline $\mathrm{pH}$ bleached pulps, or between the two kappa numbers investigated in this study and also in the observation found in previous study (8). This extraction stage kappa reduction ( $47.0 \& 50.0 \%)$ in acidic pH and (47.7 \& 49.2\%) in alkaline pH Do stages suggests that the relative bleaching of EH2013 pulps has ease of lignin removal of both unbleached kappa numbers.

The bleaching stage, chemical consumption was same during the acidic Do bleaching when compared to alkaline bleaching except sodium hydroxide and sulphuric acid consumption. The maximum chemical saving in alkaline $\mathrm{pH}$ initial chlorine dioxide bleaching was contributed by sodium hydroxide followed by sulphuric acid. This optimum temperature used in this bleaching has resulted in lower temperature of filtrate to be discharging without any cooling. The total saving in terms of chemicals and temperature reduction in initial chlorine dioxide bleaching is found to be encouraging to commercilise the alkaline $\mathrm{pH} \mathrm{ClO}_{2}$ bleaching in wood pulp.

The strength properties like tensile, tear and burst indices are given in table: II. The alkaline $\mathrm{pH}$ chlorine dioxide bleached EH2013 pulp shows 4.8\&4.5\% Tensile, 6.1 \&7.3\% Tear and $9.4 \& 8.4 \%$ Burst Index higher than Acidic $\mathrm{pH}$ bleaching of $16 \& 17 \%$ TAA cooked pulp. This shows that the bleachability of EH2012 pulp at alkaline $\mathrm{pH}$ bleaching has shown variation than acidic $\mathrm{pH}$ bleaching. The target brightness can be achieved easily, if the first treatment is done effectively by proper washing of reaction products and extracting alkali soluble compounds in a subsequent extraction stage and followed by second stage $\left(D_{1}\right)$ chlorine dioxide bleaching with increment in strength properties.

\section{Influence of fiber morphology}

Lignin derivatives can affect the physical properties of a paper, but other factors are important as well. Morphological factors, such as fiber length, width and coarseness and the flexibility of the fiber wall have large influence on pulp and paper properties. These parameters are to a large extent determined by the pulping raw material used. Pulps from different pulping raw materials and processes were compared, and differences in properties were also observed.

Pulps from Unbleached, acidic and Alkaline $\mathrm{pH}$ processes were tested, and their main wood characteristics, except the fiber width, the fines and Curl index of Alkaline $\mathrm{pH}$ bleached pulp were lower than Acidic $\mathrm{pH}$ pulp. Short and thin-walled wood fibers with low coarseness give pulp with a high number if fibers per unit mass. Pulp that contains a high number of fibers per unit weight has excellent light-scattering property. Stiff, uncollapsed fibers give high bulk to paper. Short length of fibers is the better formation. Short fibers tend to have low surface strength. High hemicellulose content and low cell wall thickness guarantee a good bonding ability for the pulp.

Information on the mechanisms of delignification at alkaline $\&$ acidic $\mathrm{pH}$, and potential environmental effects was obtained by collecting and analysing filtrates from each of the bleaching stages. The resulting data are presented in Table: VIII \& IX, the result shows that Do stage filtrate contains lower Colour (14.6 \& 15.4\%), 
Total Dissolved Solids (10.7 \& 17.9\%) and COD (14.2 \& 18.0\%), TDS inorganic, sulphate and chlorides (chart VII\&VIII) than acidic $\mathrm{pH}$ stage. These filtrate characteristics clearly indicates that higher $\mathrm{pH}$ Chlorine dioxide bleach filtrate have low Colour, TDS, and COD than the Acidic $\mathrm{pH}$ filtrate. High sulphate and low $\mathrm{pH}$ are the major contributes to filaments bulking, forming which affects the sludge settling leading to higher suspended solids carryover in secondary clarifier and performance of biological treatment $(16,17$, and 18). The lower TDS inorganic in washing filtrate with lower temperature is a major environmental benefit, because there is no commercially viable technology available to reduce TDS inorganic for large scale integrated pulp and paper mills.

\section{Figures And Tables}

Table: I. Unbleached pulp Cloned Eucalyptus Hybrid 2013 Properties

\begin{tabular}{|c|l|c|c|}
\hline S.No. & Particular & 16\%TAA & 17\%TAA \\
\hline 1 & Screened pulp yield ,\% & 51.35 & 51.20 \\
\hline 2 & Reject, \% & 0.28 & 0.12 \\
\hline 3 & Kappa number & 18.9 & 17.8 \\
\hline 4 & Pulp brightness, \%ISO & 32.3 & 32.4 \\
\hline
\end{tabular}

Table: II. EH2013 Wood bleaching conditions

\begin{tabular}{|c|c|c|c|c|c|c|c|}
\hline \multirow{2}{*}{ S.No. } & \multirow{2}{*}{ Parameters } & \multicolumn{3}{|c|}{$16 \%$ Acidic Condition } & \multicolumn{3}{|c|}{$16 \%$ Alkaline Condition } \\
\hline & & Do & Ep & $\mathbf{D}_{1}$ & Do & Ep & $\mathbf{D}_{1}$ \\
\hline 1 & Initial $\mathrm{pH}$ & 8.2 & 3.5 & 7.1 & 8.2 & 4.2 & 8.2 \\
\hline 2 & Acid /alkali addition, $\%$ & 1.00 & 0.90 & 0.00 & 0.20 & 0.45 & 0.00 \\
\hline 3 & $\mathrm{pH}$ & 3.3 & 11.4 & 7.1 & 10.9 & 11.4 & 8.2 \\
\hline 4 & $\mathrm{ClO}_{2} / \mathrm{H}_{2} \mathrm{O}_{2}$ addition, $\%$ & 1.80 & 1.00 & 0.80 & 1.80 & 1.00 & 0.80 \\
\hline 5 & $\mathrm{pH}$ & 2.2 & 10.2 & 3.7 & 5.8 & 10.5 & 5.6 \\
\hline 6 & Brightness, \%ISO & 51.4 & 68.8 & 83.4 & 53.6 & 72.9 & 85.7 \\
\hline 7 & Kappa number & 5.8 & 3.6 & 1.4 & 5.5 & 3.4 & 1.3 \\
\hline 8 & Kappa reduction , $\%$ & 69.3 & 37.9 & 61.1 & 70.9 & 38.2 & 61.8 \\
\hline
\end{tabular}

Chart: I, 16\% TAA EH2013Acidic pH bleaching

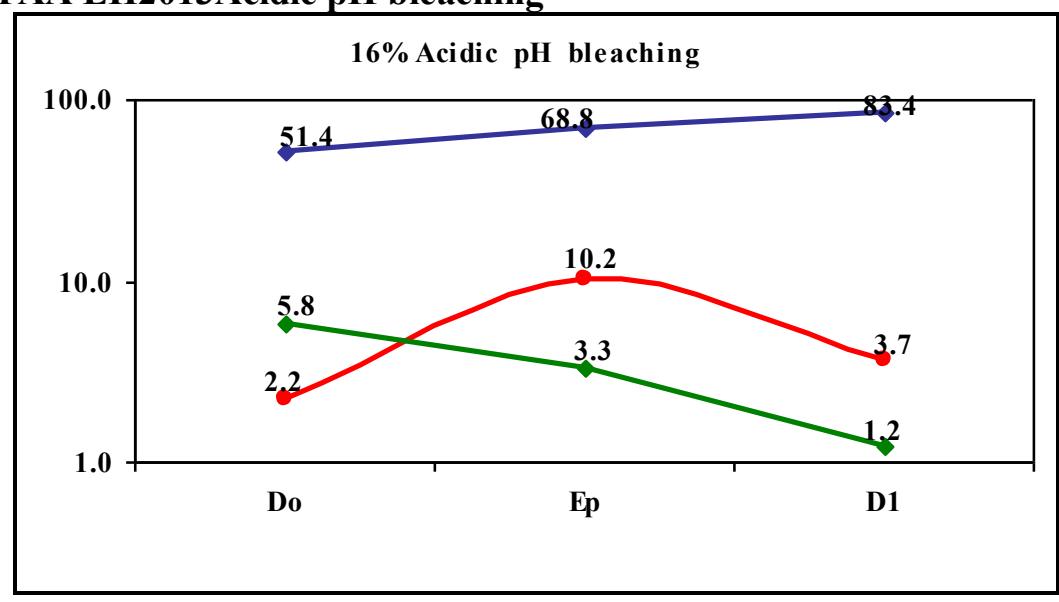

Chart: II, 16\% TAA EH2013 Alkaline pH bleaching

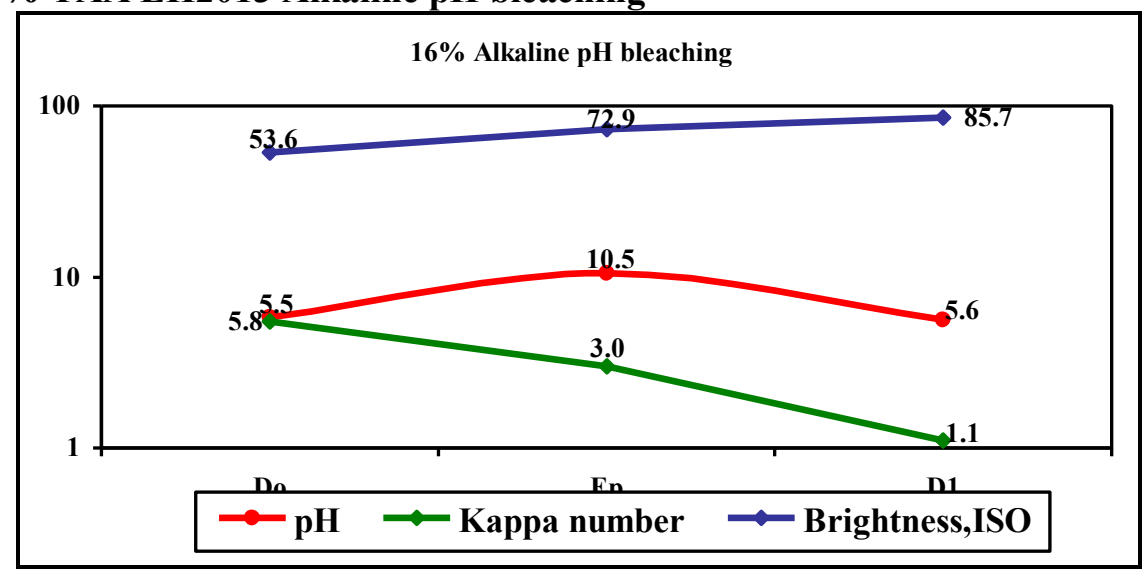




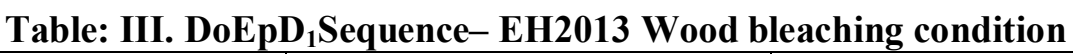

\begin{tabular}{|c|c|c|c|c|c|c|c|}
\hline \multirow{2}{*}{ S.No. } & \multirow{2}{*}{ Parameters } & \multicolumn{3}{|c|}{ 17\% Acidic Bleaching condition } & \multicolumn{3}{|c|}{ 17\% Alkaline Bleaching condition } \\
\hline & & $\mathbf{D}_{0}$ & Ep & $\mathbf{D}_{1}$ & $\mathbf{D}_{0}$ & Ep & $\mathbf{D}_{1}$ \\
\hline 1 & Initial $\mathrm{pH}$ & 8.2 & 3.8 & 7.5 & 8.2 & 4.2 & 8.2 \\
\hline 2 & Acid /Alkali addition, $\%$ & 1.00 & 0.90 & 0.00 & 0.20 & 0.45 & 0.00 \\
\hline 3 & $\mathrm{pH}$ & 3.7 & 11.0 & 7.5 & 10.8 & 11.2 & 8.2 \\
\hline 4 & $\mathrm{ClO}_{2} / \mathrm{H}_{2} \mathrm{O}_{2}$ addition, $\%$ & 1.80 & 1.00 & 0.80 & 1.80 & 1.00 & 0.80 \\
\hline 5 & $\mathrm{pH}$ & 2.2 & 10.2 & $5 . .0$ & 4.9 & 10.4 & 5.9 \\
\hline 6 & Brightness, \%ISO & 53.6 & 68.2 & 84.4 & 55.3 & 70.9 & 86.5 \\
\hline 7 & Kappa number & 5.5 & 3.4 & 1.3 & 5.3 & 3.2 & 1.3 \\
\hline 8 & Kappa reduction , $\%$ & 69.1 & 38.2 & 61.8 & 70.2 & 39.6 & 59.4 \\
\hline
\end{tabular}

Chart: III, 17\% TAA EH2013 Acidic pH bleaching

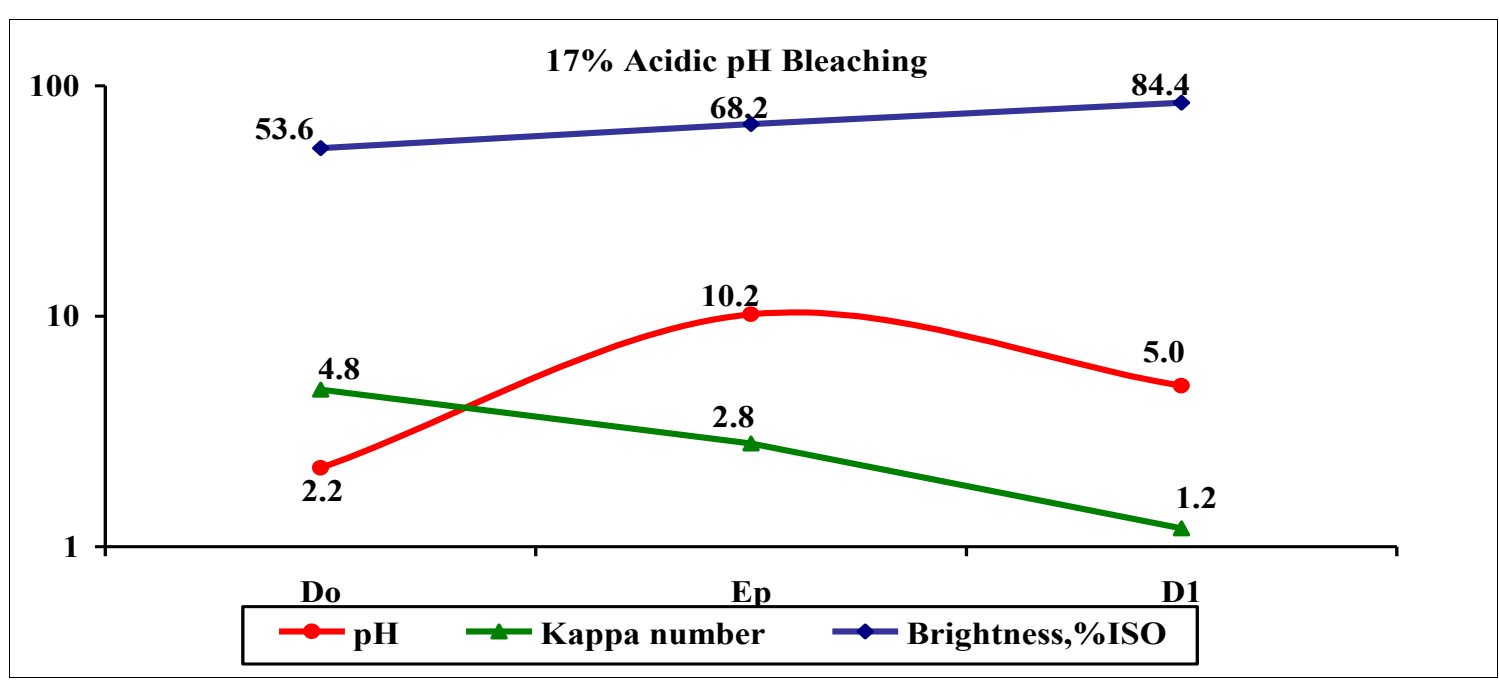

Chart: IV, 17\% TAA EH2013 Alkaline pH bleaching

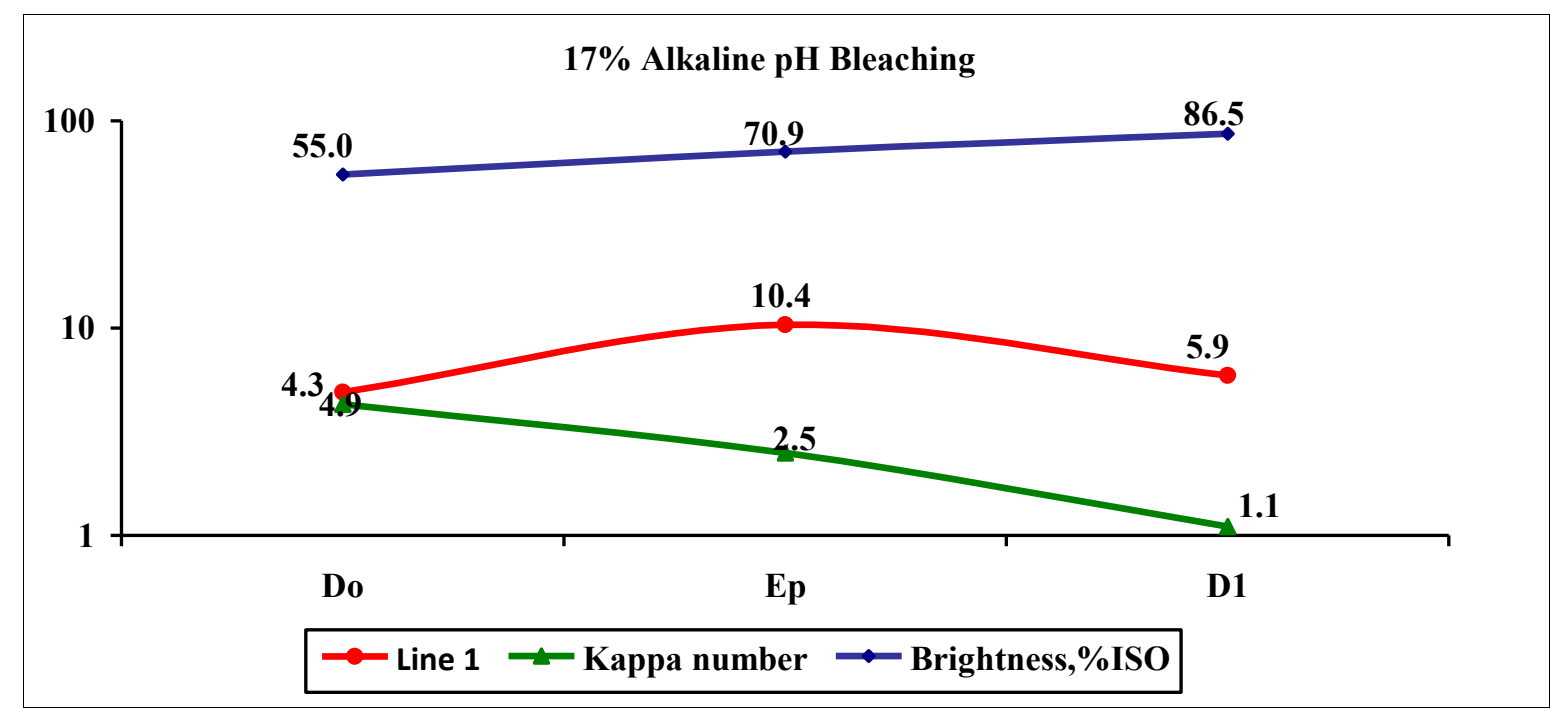

Table: IV. Strength properties of $16 \%$ TAA unbleached and bleached pulp- EH2013

\begin{tabular}{|c|l|c|c|c|c|}
\hline \multirow{2}{*}{ S. No. } & \multirow{2}{*}{ Parameters } & \multirow{2}{*}{ unit } & \multicolumn{3}{|c|}{$\mathbf{1 6}$ \% TAA Cooked Pulp } \\
\cline { 3 - 5 } & & & Unbleached & Acidic bleached & Alkaline bleached \\
\hline 1 & CSF & $\mathrm{ml}$ & 500 & 470 & $\mathbf{4 6 0}$ \\
\hline 2 & Bulk & $\mathrm{cc} \mathrm{g}^{-1}$ & 2.08 & 1.92 & $\mathbf{1 . 8 8}$ \\
\hline 3 & Tensile Index & $\mathrm{N} \mathrm{m} \mathrm{g}^{-1}$ & $\mathbf{4 9 . 8}$ & $\mathbf{4 3 . 2}$ & $\mathbf{4 6 . 1}$ \\
\hline 4 & Tear Index & $\mathrm{M} \mathrm{N} \mathrm{m}^{-1} \mathrm{~g}^{-1}$ & $\mathbf{6 . 5}$ & $\mathbf{6 . 9 4}$ & $\mathbf{2 . 1 8}$ \\
\hline 5 & Burst Index & $\mathrm{K} \mathrm{pa} \mathrm{m}^{2} \mathrm{~g}^{-1}$ & $\mathbf{2 . 3 9}$ & $\mathbf{2 . 5 3}$ & $\mathbf{2 . 6 4}$ \\
\hline
\end{tabular}


Chart: V, 16 \% TAA Cooked EH 2013 Unbleached \&bleached Pulp strength properties

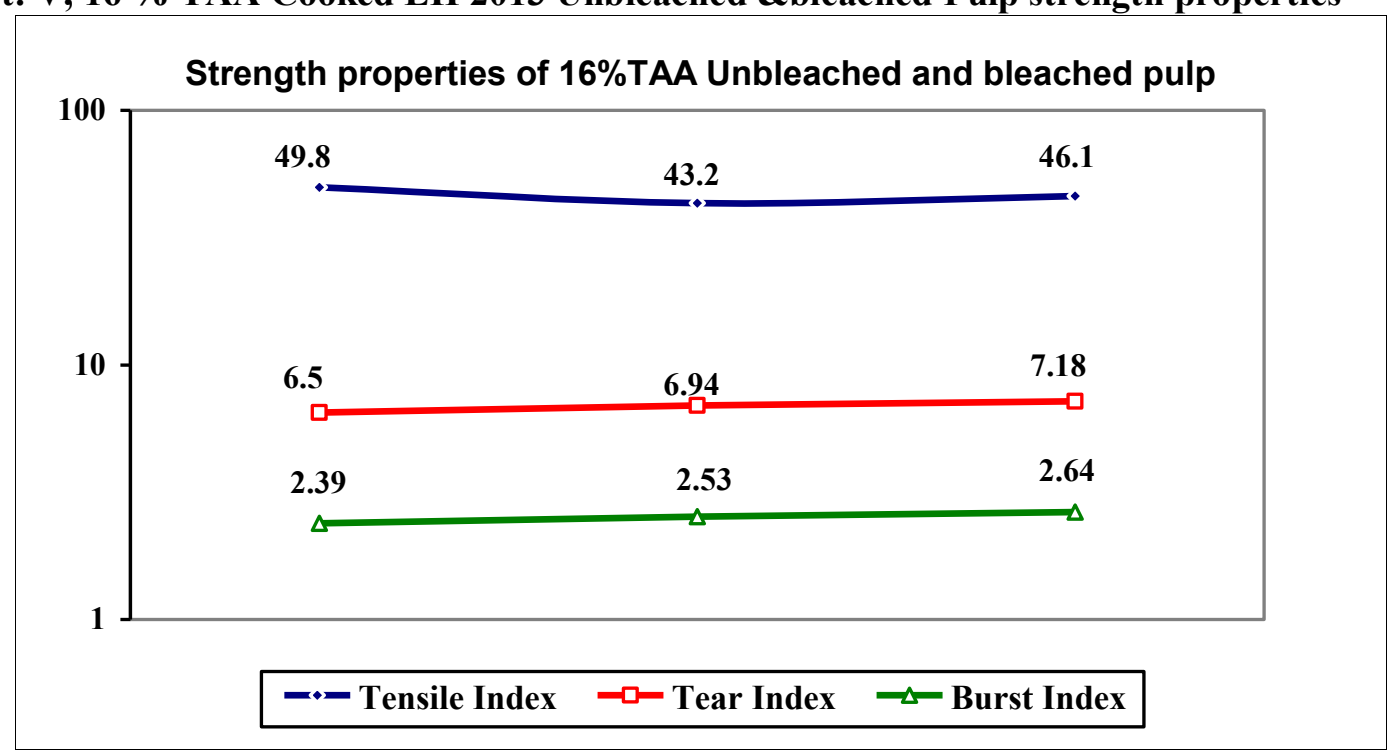

Table: V. 17\% TAA Cooked EH 2013 Unbleached \&bleached Pulp strength properties

\begin{tabular}{|c|l|c|c|c|c|}
\hline \multirow{2}{*}{ S. No. } & \multirow{2}{*}{ Parameters } & \multirow{2}{*}{ unit } & \multicolumn{3}{|c|}{$\mathbf{1 7}$ \% TAA Cooked Pulp } \\
\cline { 3 - 6 } & & & Unbleached & Acidic bleached & Alkaline bleached \\
\hline 1 & CSF & $\mathrm{ml}$ & 480 & 470 & $\mathbf{4 6 0}$ \\
\hline 2 & Bulk & $\mathrm{cc} \mathrm{g}^{-1}$ & 2.08 & 1.96 & $\mathbf{1 . 9 0}$ \\
\hline 3 & Tensile Index & $\mathrm{N} \mathrm{m} \mathrm{g}^{-1}$ & $\mathbf{4 9 . 0}$ & $\mathbf{4 3 . 0}$ & $\mathbf{4 4 . 6}$ \\
\hline 4 & Tear Index & $\mathrm{M} \mathrm{N} \mathrm{m}^{-1} \mathrm{~g}^{-1}$ & $\mathbf{6 . 4}$ & $\mathbf{6 . 5}$ & $\mathbf{7 . 1}$ \\
\hline 5 & Burst Index & $\mathrm{K} \mathrm{pa} \mathrm{m}^{2} \mathrm{~g}^{-1}$ & $\mathbf{2 . 6 5}$ & $\mathbf{2 . 4 2}$ & $\mathbf{2 . 4 7}$ \\
\hline
\end{tabular}

Chart: VI, 17 \% TAA Unbleached \&bleached Pulp strength properties

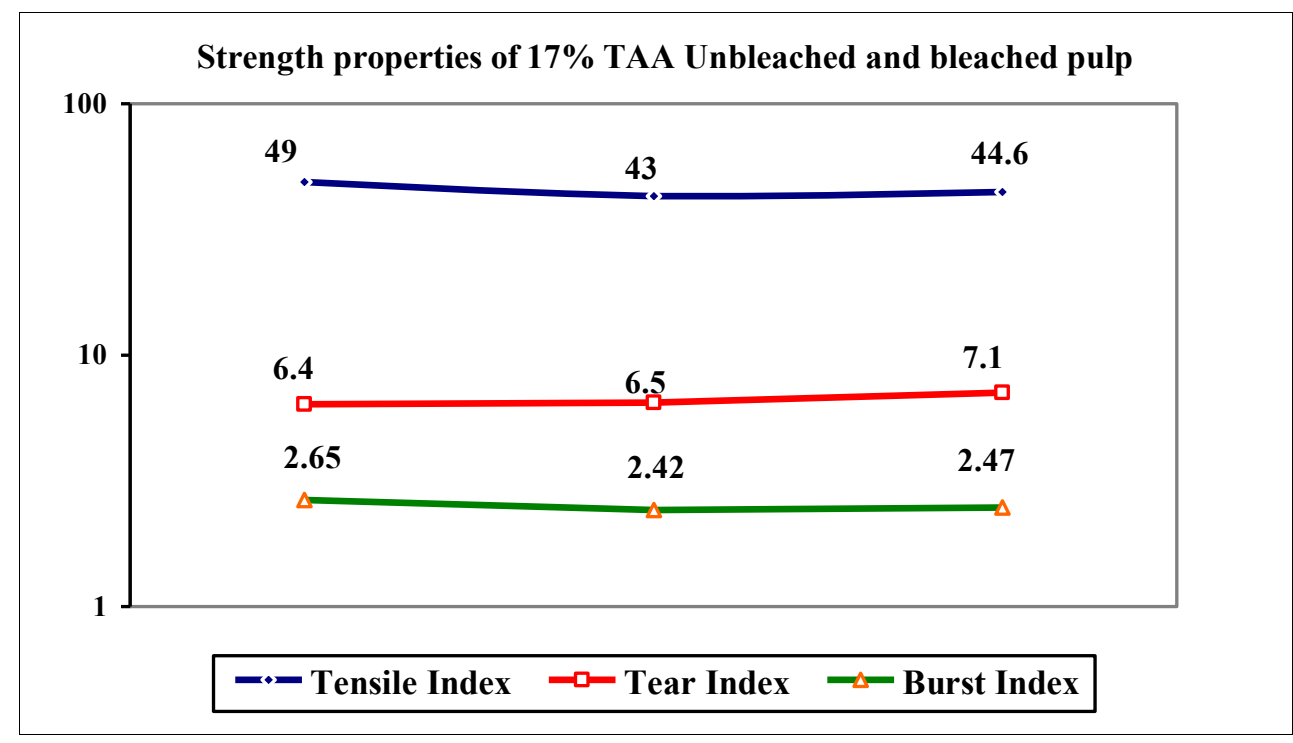

Table: VI. Fiber Morphology of 16\%TAAUnbleached and Bleached pulp

\begin{tabular}{|l|c|c|c|c|}
\hline EH2013, 16\%TAA & Fiber length, mm & Fiber with, $\mu \mathrm{m}$ & Fine, \% & Curl, \% \\
\hline Unbleached & 0.77 & 14.44 & 8.57 & 11.3 \\
\hline Acidic pH bleached & 0.74 & 14.08 & 9.36 & 11.9 \\
\hline Alkaline pH bleached & 0.74 & 14.14 & 9.36 & 11.6 \\
\hline
\end{tabular}


Table: VII. Fiber Morphology of 17\%TAAUnbleached and Bleached pulp

\begin{tabular}{|l|c|c|c|c|}
\hline EH2013, 17\% TAA & Fiber length, $\mathbf{m m}$ & Fiber with, $\mu \mathrm{m}$ & Fine, $\%$ & Curl,\% \\
\hline Unbleached & 0.77 & 14.59 & 8.46 & 11.5 \\
\hline Acidic pH bleached & 0.74 & 14.18 & 9.06 & 12.3 \\
\hline Alkaline pH bleached & 0.74 & 14.25 & 8.96 & 11.5 \\
\hline
\end{tabular}

Table: VIII. Effluent Characteristics of bleaching filtrate - EH2013

\begin{tabular}{|c|c|c|c|c|c|c|c|c|}
\hline \multirow[b]{2}{*}{ S.No } & \multirow[b]{2}{*}{ Parameters } & \multirow[b]{2}{*}{ Unit } & \multicolumn{3}{|c|}{$16 \%$ TAA Acidic filtrate } & \multicolumn{3}{|c|}{ 16\%TAA Alkaline Filtrate } \\
\hline & & & $\mathbf{D}_{0}$ & Ep & $\mathbf{D}_{1}$ & $\mathbf{D}_{0}$ & Ep & $\mathbf{D}_{1}$ \\
\hline 1 & Colour & Pt. Co., & 1475 & 1340 & 480 & 1360 & 1250 & 450 \\
\hline 2 & Total dissolved solids & $\mathrm{mg} / \mathrm{l}$ & 3788 & 3420 & 1896 & 3346 & 2894 & 1602 \\
\hline 4 & TDS Inorganic & $\mathrm{mg} / \mathrm{l}$ & 2676 & 2482 & 1410 & 2234 & 2066 & 1184 \\
\hline 5 & TDS Inorganic & $\%$ & 70.6 & 72.6 & 74.4 & 66.8 & 71.4 & 73.9 \\
\hline 6 & Total COD & $\mathrm{mg} / \mathrm{l}$ & 1707 & 1816 & 955 & 1390 & 1462 & 929 \\
\hline 8 & Calcium Hradness & $\mathrm{mg} / \mathrm{l}$ & 940 & 920 & 560 & 780 & 840 & 480 \\
\hline 9 & Magnesium Hardness & $\mathrm{mg} / \mathrm{l}$ & 300 & 300 & 280 & 312 & 294 & 320 \\
\hline 10 & Chlorides as $\mathrm{Cl}$ & $\mathrm{mg} / \mathrm{l}$ & 1400 & 1250 & 820 & 1270 & 1050 & 860 \\
\hline
\end{tabular}

Chart: VII. Effluent Characteristics of 16\% TAA bleaching filtrate-EH2013

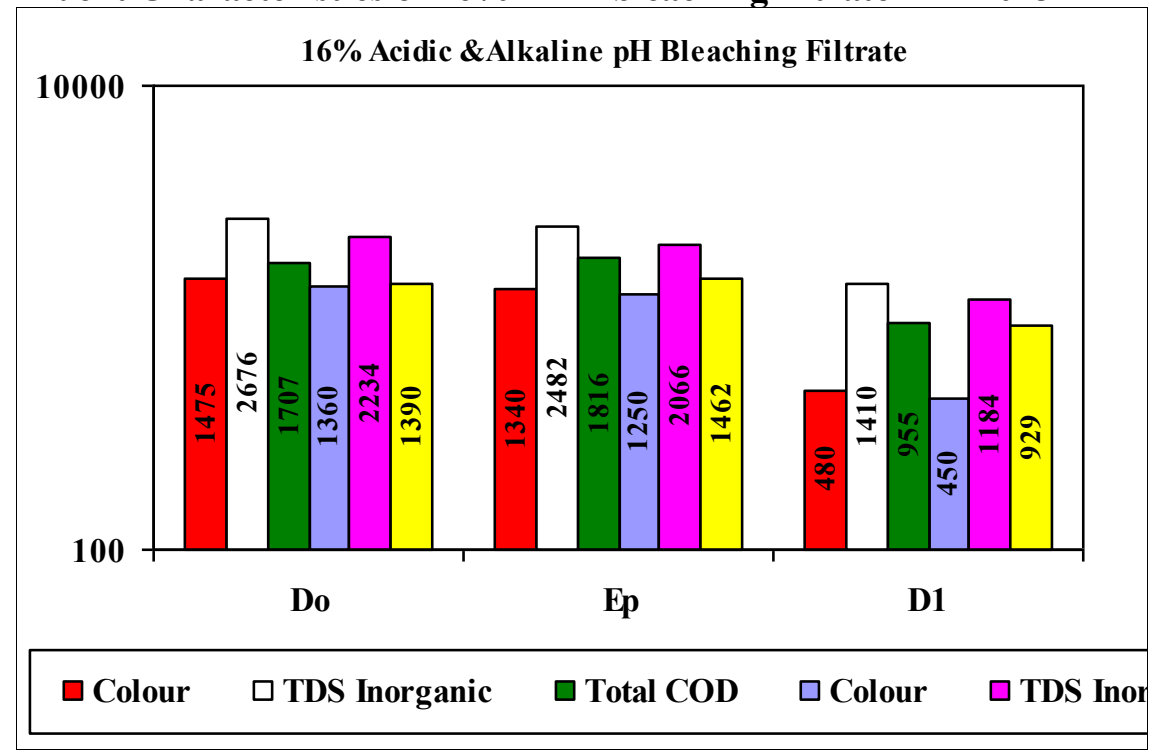

Table: IX. Effluent Characteristics of bleaching filtrate - EH2013

\begin{tabular}{|c|c|c|c|c|c|c|c|c|}
\hline \multirow[b]{2}{*}{ S.No } & \multirow[b]{2}{*}{ Parameters } & \multirow[b]{2}{*}{ Unit } & \multicolumn{3}{|c|}{ 17\% TAA Acidic Filtrate } & \multicolumn{3}{|c|}{ 17\% TAA Alkaline Filtrate } \\
\hline & & & $\mathbf{D}_{0}$ & Ep & $\mathbf{D}_{1}$ & $\mathbf{D}_{0}$ & Ep & $\mathbf{D}_{1}$ \\
\hline 1 & Colour & Pt. Co., & 1400 & 1200 & 460 & 1150 & 1020 & 430 \\
\hline 2 & Total dissolved solids & $\mathrm{mg} / \mathrm{l}$ & 3126 & 2852 & 1966 & 2686 & 2504 & 1580 \\
\hline 4 & TDS Inorganic & $\mathrm{mg} / \mathrm{l}$ & 2278 & 2012 & 1374 & 1882 & 1804 & 1126 \\
\hline 5 & TDS Inorganic & $\%$ & 72.9 & 70.5 & 69.9 & 70.0 & 72.0 & 71.3 \\
\hline 8 & Calcium Hardness & $\mathrm{mg} / \mathrm{l}$ & 1140 & 820 & 470 & 920 & 750 & 400 \\
\hline 9 & Magnesium Hardness & $\mathrm{mg} / \mathrm{l}$ & 340 & 320 & 310 & 324 & 310 & 320 \\
\hline 10 & Chlorides as $\mathrm{Cl}$ & $\mathrm{mg} / \mathrm{l}$ & 1350 & 1260 & 750 & 1230 & 1200 & 760 \\
\hline
\end{tabular}

Chart: VIII. Effluent Characteristics of 17\% TAA bleaching filtrate - EH2013 


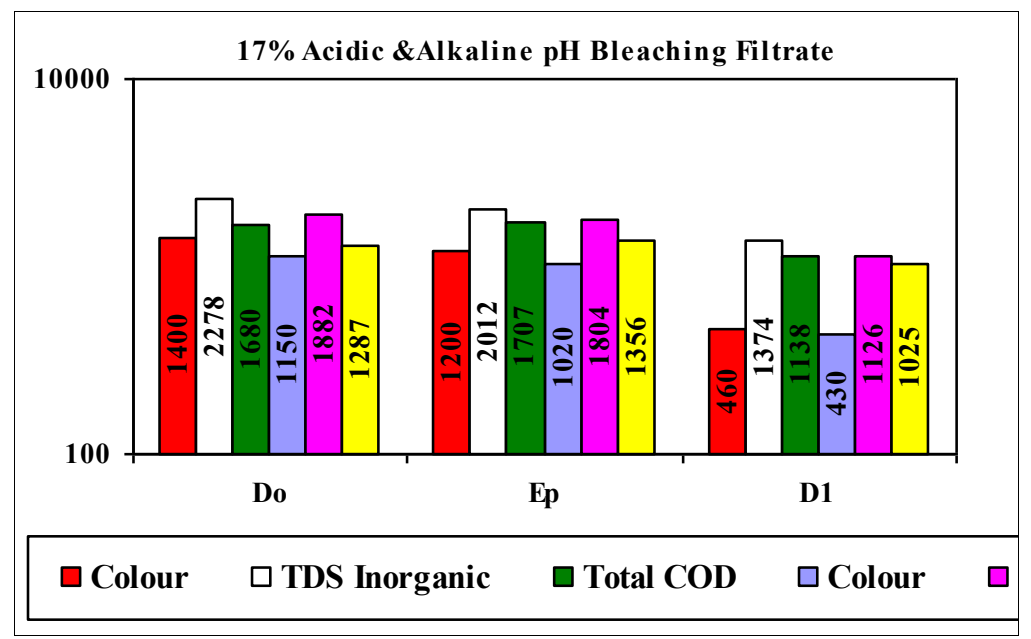

\section{Conclusions}

The efficient and environmentally beneficial to manufacture bleached Eucalyptus pulp is achieved by terminating cook at slightly higher kappa and bleaching with the alkaline $\mathrm{pH}$ initial chlorine dioxide bleaching at optimum temperature with $\mathrm{D}_{0} \mathrm{EpD}_{1}$ sequence, without ODL. The investment of oxygen delignification reactor and press cost would be saved. But the oxidation efficiency of same $\mathrm{ClO} 2$ consumption in EH2012 was slightly lower than the Casuariana cloned wood pulp bleaching. The strength properties of Alkaline $\mathrm{pH}$ bleached pulp are compareable with Acidic $\mathrm{pH}$ bleached pulp. The bleached filtrate characteristics were lower during the alkaline bleaching than the acid bleaching filtrate of EH2013 pulps. The maximum chemical saving is the lower sodium hydroxide consumption in alkaline $\mathrm{pH}$ pulp and eliminating sulphuric acid in alkaline $\mathrm{pH}$ bleaching sequences . Rapid alkaline $\mathrm{pH}$ initial $\mathrm{ClO}_{2}$ (Do stage) bleaching of EH2013 pulp delignifies effectively and is beneficial in reducing the amount of AOX formed in the Do stage of the bleaching sequence. At high $\mathrm{pH} \mathrm{ClO}_{2}$ bleaching may possibly maximize extractives removal without brightness loss which decreases the deposit potential in paper machine and lesser refining energy.

\section{Acknowledgement}

Authors are thankful to The Institute of Forest Genetics and Tree Breeding (IFGTB), Coimbatore, Tamilnadu Newsprint and Papers Limited (TNPL), Kagithapuram, karur, and Kandaswamy Kandars College Principal and management for giving permission to submit this paper in the Journal of Wood Science.

\section{Journal Papers:}

\section{References}

[1]. $\quad$ Axegard, P., "Improvement of Bleach Plant Effluent by Cutting Back on C12." Pulp and Paper Canada, Vol.90, 1989, pp. 78-81.

[2]. Carruthers, George., In the Paper Making. Garden City Press Coop., Toronto, 1947, p.712.

[3]. Hart, P.W., The Chemical Versus energy tug of war: a Pulp mill perspective.TAPPIJ, 10 (7), pp. 37 -42, 2011

[4]. 10. Camilla Asplund., Ulf Germgard., (1991). Bleaching of Eucalypt karft Pulp. Part 3, APPIT A, 44 (2), pp, 95 - 99.

[5]. 11. Douglas W. Reeve., Kathleen M. Weishar., (1991). Chlorine dioxide delignification - process variables. TAPPI Journal, pp, 164 -167 .

\section{Proceeding papers}

[6]. Basta, J., et al. "Low AOX, Possibilities, and Consequences." 1989 Pulping Conference, Tappi Press, Atlanta, 1989, pp. 427-436

[7]. Runge, T., Ragauskas, A., Froass, P., Advances in Understanding the Basics of the First Alkaline Extraction Stage in Bleaching. 1997 Pulping Conference, San Francisco. TAPPI PRESS, Atlanta, 1997, pp.603-608.

[8]. Sankaralingam, P., Sankar, A., Alkaline Chlorine dioxide bleaching of Casuarina (CJ9) wood and its environmental Impact, Presented at IPPTA AGM Conference, Chennai, 2013, pp.176 -181.

[9]. Sankaralingam,P., Chinnaraj ,S., and subrhamanyam, S.V., (2012). Alkaline Bleaching of Mixed Hardwood to improve Economical and Environmental Impact ,pp.69-76, Presented at the $2^{\text {nd }}$ Paper Plus Conference on Pulp, Paper and Allied Industries , Ciombatore, India, Nov.2012.

[10]. Rudatin, S., Sen, Y.L., Woerner, D.L., Association of Kraft Lignin in Aqueous Solutions. Lignin Properties and Materials. ACS Symposium Series 397. Edited by W. Glasser and S. Sarkanen, 1989, pp.145-154.

[11]. Dutta, S., Garver, T., Sarkanen, S., Modes of Association between Kraft Lignin Components. Association of Kraft Lignin in Aqueous Solutions.

[12]. Lignin Properties and Materials. ACS Symposium Series 397. Edited by W. Glasser and S. Sarkanen, 1989, pp.155-176.

[13]. Richard M., (2003). Activated sludge microbiology problems and their control, Presented at the $20^{\text {th }}$ Annual USEPA National Operator Trainers Conference, Buffalo, NY, USA.

[14]. Richard M., (1997). Recent Changes in the Prevalence and Causes of Bulking Filamentous Bacteria in Pulp and Paper Mill Activated Sludge Systems. proceedings of the 1997 TAPPI Environmental Conference, p. 553, Minneapolis- Saint Paul, MN. USA. 
[15]. Flippen, T.H.,and W.W. Eckenfelder, (1994). Effect of Elevated Temperature on the Activated Sludge Process. Proceedings of the 1994 TAPPI Environmental Conference, p. 947, Portland, or USA.

Books:

[16]. Pulp Bleaching: Principles and Practice, TAPPI Press, Eds., Dence, C., and Reeve, D., (1996).

[17]. Herbert Sixta ., Hand book of pulp, WILEY-VCH Verlag, Gmbh \& Co, KGAA Weinhem

[18]. Jenkins, D., M.G. Richard and G.T. Daigger (1993) Manual on the Causes and Control of Activated Sludge Bulking and Foaming, $2^{\text {nd }}$ Ed., Lewis Publishers, Boca Raton, FL, USA. 